Gábor Pusztai

\title{
Van exportbruid van de VOC tot de rijkste vrouw van de republiek
}

\author{
Anneloes Timmerije: De mannen van Maria.
} Amsterdam: Querido, 2019.

De auteur, Anneloes Timmerije (1955) is vooral bekend als journaliste en schrijfster van literaire en historische non-fictie. Voor haar debuut in 2005, een verhalenbundel met de titel Zwartzuur ontving zij de Vrouw\&Cultuur Debuutprijs. Ze schreef in 2010 de roman De grote Joseph, in 2013 de verhalenbundel Slaapwandelen bij daglicht en in 2014 publiceerde zij samen met Charles den Tex de historische roman Het vergeten verhaal van een onwankelbare liefde in oorlogstijd. Het idee voor haar De mannen van Maria kreeg zij tijdens een ontmoeting met een oude vriend in Leiden. De oude vriend, Menno Witteveen, promoveerde toen op Antonio van Diemen (1593-1645) gouverneur-generaal van de VOC. Timmerije las het proefschrift en vond een stukje over Maria van Aelst. De figuur van Maria fascineerde haar. Zij was een onconventionele, intelligente vrouw, de grande dame van Batavia.

De historische roman van Anneloes Timmerije vertelt haar verhaal, het leven van Maria van Aelst. Zij was een meisje uit Steenbergen dat in 1625 in het kader van een volksplanting van de VOC samen met nette, Hollandse meisjes naar Batavia werd verscheept. De bedoeling was dat zij in Batavia met VOC-dienaren zouden trouwen en zodoende een Nederlandse kolonie zouden vormen. Gouverneur-generaal Jan Pieterszoon Coen (1587-1629) wilde in 1623 de Heren Zeventien overtuigen dat Batavia een Nederlandse nederzetting moest zijn met Nederlandse man- 
nen en vrouwen, Nederlandse kooplieden en Nederlandse ambachtslui. Men wilde hiermee vooral de gebruikelijke praktijk van concubinaat met inheemse of halfbloed vrouwen doorbreken. Vooral weesmeisjes werden naar de aankomende kolonie gestuurd met de belofte hier een rijke partij te kunnen trouwen in een aards paradijs. Maar Batavia was geen aards paradijs, zoals vele dachten. Het was eerder een malarianest, omringd door vijandige inheemsen.

'Als mijn vader had geweten hoe het in Batavia was, had hij mij nooit weggestuurd. Het voormalige moeras van Jacarta, in 1619 veroverd op Bantam, de westelijke provincie van Java, was een hete puinhoop vol steekmuggen en geweld.' (p. 41.)

De beschrijving van Maria van de toenmalige havenstad is treffend. Batavia werd door Coen, de vierde gouverneur-generaal van de VOC, in 1619 met geweld veroverd. Coen schakelde de Engelse concurrentie uit en dwong de inheemse vorst de Nederlandse aanwezigheid te accepteren. Het idee van de volksplanting werd al gouw overboord gegooid en men keerde terug naar het bezworen concubinaat. Maar Maria bleef in Batavia en trouwde volgens plan met de koopman Johan Libener. Anderhalf jaar later, voor haar twintigste verjaardag, was ze al weduwe. Hij stierf aan een hartkwaal. Met haar geërfde kapitaal begon ze zelf handel te drijven, en wel in diamanten. Ze hertrouwde met de schatrijke en invloedrijke koopman Bartholomeus Havickszoon Kunst. Hij stierf binnen twee jaar in 1629, tijdens de belegering van de stad, aan een tropische ziekte. Haar derde man werd Antonio van Diemen, de latere gouverneur-generaal. Maria trouwde met steeds rijkere en machtigere mannen en werd zelf rijker en rijker aan de diamantenhandel, maar ze bleef kinderloos. Na de dood van haar derde man verliet Maria Batavia en keerde terug naar Nederland. Zij was een schatrijke weduwe, de "ex-koningin van Batavia" en met haar achtendertig jaar nog steeds een aantrekkelijke vrouw. Natuurlijk werd zij ten huwelijk gevraagd. De vierde in rij van de echtgenoten was de rijke en charmante Carel Constant. Maria werd moeder in 1647, veertig jaar oud. Haar dochtertje werd Anna Maria gedoopt. Het kindje stierf vijf dagen na haar geboorte. Een jaar later werd vrede gesloten met de Spanjaarden. De Tachtigjarige Oorlog was afgelopen, de Republiek was een onafhankelijk land. In 1655 verloor Maria haar vierde man. Zij ontmoette haar laatste echtgenoot in Utrecht. Ze trouwde met de oud-burgemeester en medeoprichter van de Universiteit Utrecht, Gijsbert van der Hoolck. Maria overleed als een schatrijke vrouw in 1674, in Den Haag. Zij behoorde toen tot de honderd rijkste mensen van de Republiek. 


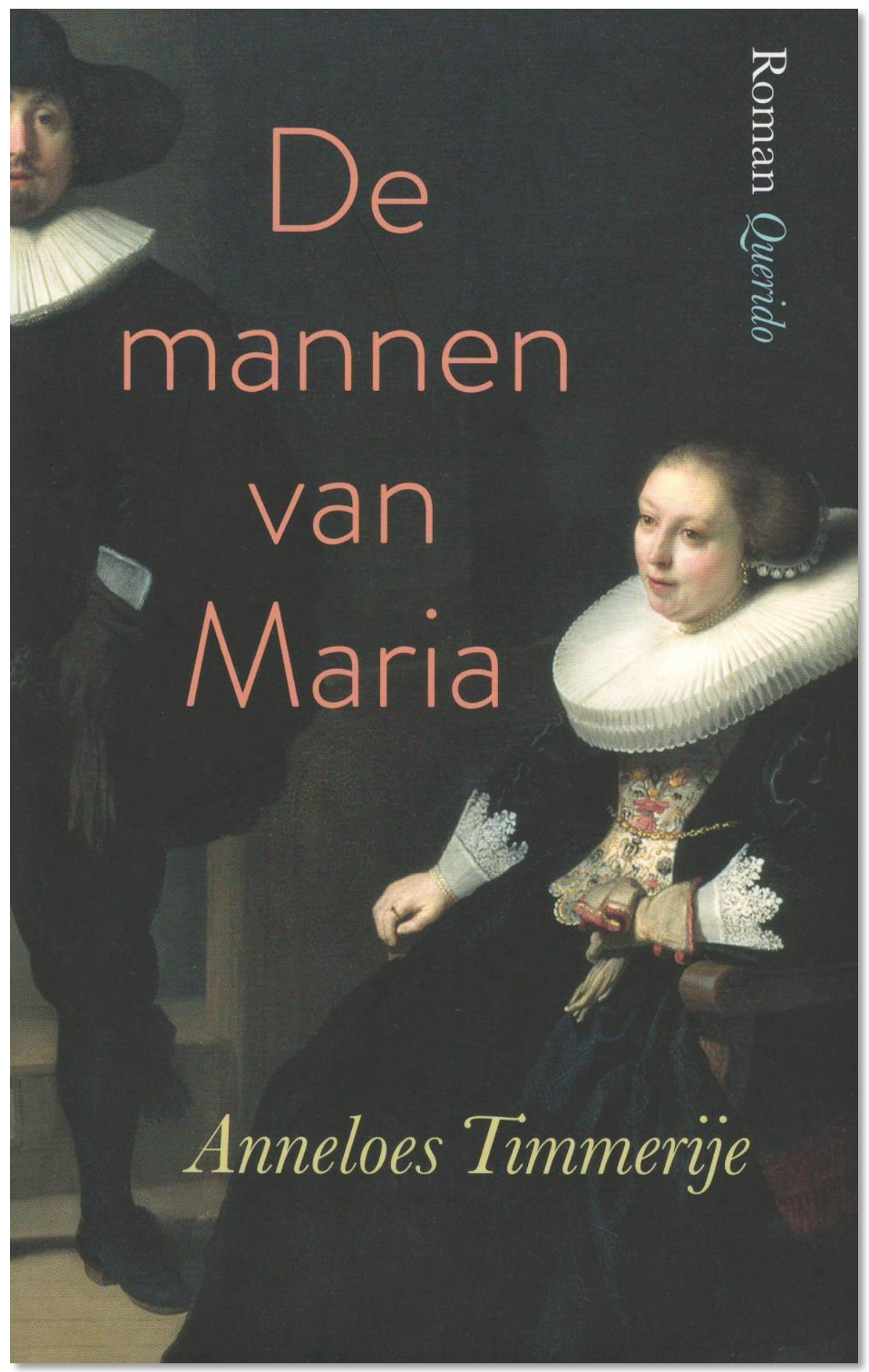


Omdat zij zo rijk was, leek het onwaarschijnlijk dat er geen portret van haar werd geschilderd. Timmerije ging met de hulp van de beeldende kunstenaar Rudolf Smeets op zoek naar het schilderij van Maria. Uiteindelijk werd een doek van Rembrandt gevonden, met de titel A Lady and a Gentleman in Black. Of "The Lady" op het schilderij inderdaad Maria van Aelst was, kon niet worden bewezen. Er zijn wel aanwijzingen dat "The Gentleman" eventueel Antonio van Diemen zou kunnen zijn. Ook de datum (1632) klopt, toen was het echtpaar in Amsterdam. Maar een onomstotelijk bewijs kon niet gevonden worden. Het doek hing in een museum in Boston, maar werd in 1990, in de grootste kunstroof aller tijden, samen met andere schatten gestolen. Het doek is op de omslag van het boek afgedrukt.

Het verhaal van Maria is een indrukwekkende en met vaart vertelde historische roman, met een ongebruikelijk perspectief voor de $17^{\text {de }}$ eeuw: dat van een vrouw. Daarin ligt de sterkte en ook de zwakte van de roman. De gebeurtenissen en personages, vooral die van Van Diemen, zijn nauwkeurig beschreven. Waar historische gegevens ontbraken, vooral over Maria, werden de hiaten gevuld met de fantasie van de auteur. Dat bracht de schrijfster wel eens in verlegenheid en er schemert somtijds een $21^{\text {ste }}$ eeuwse visie in het $17^{\text {de }}$ eeuwse verhaal door. 